\title{
Comparison of outcomes of supracondylar femur fractures treated with locking compression plate vs supracondylar nail
}

\author{
Shroff A. S. ${ }^{1}$, Bhamare D. S. ${ }^{2}$, Herode P. ${ }^{3}$, Sadaria M. H. ${ }^{4}$, Patel J. M. ${ }^{5}$ \\ ${ }^{1}$ Dr. Abhijeet Sudhir Shroff, Associate Professor, ${ }^{2}$ Dr. Dhammapal Sahebrao Bhamare, Associate Professor, ${ }^{3}$ Dr. Prafulla \\ Herode, Associate Professor, ${ }^{4}$ Dr. Mohan Hansraj Sadaria, Senior Consultant and Orthopaedic Surgeon, Surat, Assistant \\ Professor, ${ }^{5}$ Dr. Jeegar Mohan Patel, PG Resident, all authors are affiliated with Department of Orthopaedics, Dr. D Y Patil \\ Medical College, \& Research Centre, Pune, Maharashtra, India.
}

Address for Correspondence: Dr. Dhammapal Sahebrao Bhamare, Associate Professor, Department of Orthopaedics, Dr. D.Y. Patil Medical College, \& Research Centre, Pune, Maharashtra, India. Email: drbhamareds@yahoo.co.in

\begin{abstract}
Objective: To compare the outcomes of supracondylar femur (SC) fractures treated with locking compression plate (LCP) with supracondylar nail (SCN). Methods: Analysis of 90 cases was done out of which 45 were treated with supracondylar nail and 45 with LCP. Results: Results were graded according to Schatzker and Lambert criteria. In LCP group 28 (62.22\%) had excellent, $12(26.66 \%)$ had good, $2(4.44 \%)$ had Fair and $3(6.66 \%)$ had poor results while in SCN group 22 had excellent (48.88\%), 9 had good (20\%), 6 had fair (13.33\%) and 8 had poor (17.77\%) results. Conclusion: Locking condylar plate group had the best functional result followed by SCN group according to Schatzker and Lambert criteria.
\end{abstract}

Keywords: Supracondylar femur fractures, LCP, SCN, Schatzker and Lambert criteria

\section{Introduction}

Supracondylar femur fracture is one of the most common injuries of the lower extremity which many timesinvolves damage to the articular cartilage of the knee joint. Fractures of the distal femur comprise $4-6 \%$ of all femoral fractures $[1,2]$. One end of spectrum includes patients < 40 years of age, with high male preponderance due to high energy trauma like road traffic accidents or fall from height. The other end of spectrum includes patients $>50$ years of age with female preponderance due to low energy trauma with predisposing factors like osteoporosis $[3,4]$. Supracondylar femur fracture is challenging even when treated with new fixation techniques and implants. Currently treatment of choice for supracondylar femoral fractures is usually operative, while nonsurgical treatments are seldom used and reserved for morbid patients. The operative methods include the use of either fixed angle blade plate (FABP), compression screw systems (Locking compression plate; LCP), condylar buttress plates, intramedullary nailing systems (Supracondylar nailing; SCN), external fixation or modular distal femoral replacement prosthesis [5].

Widely used classification of supracondylar fractures is the one described by Müller which was further updated by the AO group [6].

\section{Aims and Objectives}

To compare the outcomes of supracondylar femur fractures treated with locking compression plate (LCP) with supracondylar nail (SCN).

\section{Material and Methods}

\section{Study design}

It was a prospective study.

Computer generated random numbers were used for Randomization.

Total number of cases studied were 99 out of which 90 were included for final analysis.

\footnotetext{
Manuscript Received: $20^{\text {th }}$ Jully 2017

Reviewed: $30^{\text {th }}$ Jully 2017

Author Corrected: $8^{\text {th }}$ August 2017

Accepted for Publication: $17^{\text {th }}$ August 2017
} 
Place of study- Dr. D. Y. Patil Medical College and Hospital, Pune.

Duration of study- April 2015 to January 2017

\section{Inclusion criteria}

1. All types of S.C fractures included in AO classification.

2. Gustilo Anderson classification 1., 2., and 3A

3. Age- 18 to 85 years

4. Patients of both gender were included.

\section{Exclusion criteria}

1. Open fractures type III B, III C and neurologically compromised patients

2. Paediatric age group

3. Pathological fractures

4. Previous surgery in and around knee joint

\section{Implants:}

Retrograde Locked Intramedullary Nail, Locking Compression Plate, Cortical and Cancellous Screws of all sizes and range.

\section{Instruments:}

Reamer, Bone Awl, Schatz Screw, Tunneler/Bristo, Drill Bit of 3.2mm, $4.0 \mathrm{~mm}$ and $4.3 \mathrm{~mm}$, Drill Sleeve, Trocar, Depth Gauge, Tap 4.5mm, Tap Sleeve, Screw Driver, Plate Bender, C-Arm Image Intensifier. The common indications for the use of LCP plate are as follows: short distal fragment, C2 and C3 fracture patterns, failed closed reduction with retrograde IM nailing, salvage implant for revision surgery, severe osteoporosis and severe degenerative changes of the knee [8,9,10,11,12].

The common indications for the use of retrograde IM nailing for the treatment of distal femur fractures are[21,24,26,27]; Distal femur fracture AO type A, C1 and C2, open wound around fracture, bilateral femur fractures, unilateral segmental fracture with morbid obesity.

\section{Treatment protocol:}

1. Neurovascular status was monitored.

2. Standard Antero posterior and lateral plain X-ray including knee joint.

3. Upper tibial skeletal traction or above knee back slab whenever indicated.

4. CT scan for pre-operative planning if indicated.

5. Debridement for Open wounds was done within 6 hours.

6. Routine Pre-operative investigations were done along with physician fitness for surgery in all cases.

7. Patients were managed by closed reduction or open reduction using $\mathrm{C}$-arm (Image Intensifier).

8. CPM (Continuous passive movement) started after 3 weeks after surgery, once the pain was tolerable.

9. Clinical follow up was done at 2 weeks, 6 weeks, 3 months, 6 months and 1 year.

10. X-rays were ordered post operatively and at 6 weeks, 2 months, 6 months and 1 year.

11. Partial weight bearing was started after 3-6weeks.

12. Result graded according to Schatzker and Lambert Criteria[7]

Table-1: Schatzker and Lambert criteria [7].

\begin{tabular}{|c|c|}
\hline Grading & Description \\
\hline Excellent & $\begin{array}{r}\text { All of the following: loss of flexion, }<10^{\circ} ; \text { full extension; no varus, valgus, or rotatory } \\
\text { deformity; no pain; perfect joint congruency }\end{array}$ \\
\hline Good & $\begin{array}{r}\text { No more than any } 1 \text { of the following: loss of flexion, }>20^{\circ} ; \text { loss of extension, }>10^{\circ} ; \\
\text { varus deformity, }>5^{\circ} ; \text { valgus deformity, }>10^{\circ} ; \text { minimum pain }\end{array}$ \\
\hline Fair & Any 2 of the criteria listed in the previous category \\
\hline Failure & $\begin{array}{r}\text { Any of the following: flexion, } \leq 90^{\circ} ; \text { varus deformity, }>10^{\circ} ; \text { valgus deformity, }>15^{\circ} ; \\
\text { joint in congruency; disabling pain, irrespective of radiographic appearance }\end{array}$ \\
\hline
\end{tabular}




\section{Original Research Article}

\section{Results}

Out of Ninety-nine cases 48 were treated by distal femur locking plate and were designated as LCP group. Rest 51 were treated by supracondylar nail and were included in SCN group. Total five patients were lost to follow up. 2 from LCP group and 3 from SCN group. Hence, we randomly selected 45 patients from each group for the study.

Results were graded according to Schatzker and Lambert criteria [7]. In LCP group 28 (62.22\%) showed excellent, 12 (26.66\%) had good, 2 (4.44\%) had Fair and $3(6.66 \%)$ had poor results while in SCN group 22 achieved excellent (48.88\%), 9 good (20\%), 6 fair (13.33\%) and 8 achieved poor $(17.77 \%)$ results.

Table- 2: Distribution of LCP treated group and SCN treated group according to age, sex, mode of trauma, types and complications.

\begin{tabular}{|c|c|c|c|}
\hline Type & Subtype & $\begin{array}{c}\text { LCP GROUP } \\
\text { (Number/Percentage) }\end{array}$ & $\begin{array}{c}\text { SCN } \\
\text { GROUP(Number/Percentage) }\end{array}$ \\
\hline \multirow[t]{3}{*}{ Age group } & $20-40$ & $12(26.66 \%)$ & $11(24.44 \%)$ \\
\hline & $40-60$ & $19(31.11 \%)$ & $19(31.11 \%)$ \\
\hline & $60-80$ & $14(26.67 \%)$ & $15(33.33 \%)$ \\
\hline \multirow[t]{2}{*}{ Sex } & Male & $29(64.44 \%)$ & $31(68.88 \%)$ \\
\hline & Female & $16(35.55 \%)$ & $15(33.33 \%)$ \\
\hline \multirow{2}{*}{$\begin{array}{l}\text { Mechanism of } \\
\text { injury }\end{array}$} & High energy & $28(62.22 \%)$ & $27(60 \%)$ \\
\hline & Low energy & $17(37.77 \%)$ & $18(40 \%)$ \\
\hline \multirow{2}{*}{$\begin{array}{l}\text { Type of } \\
\text { fracture }\end{array}$} & Close & $26(57.77 \%)$ & $26(57.77 \%)$ \\
\hline & Open & $19(42.22 \%)$ & $19(42.22 \%)$ \\
\hline \multirow[t]{2}{*}{ Infection rate } & Superficial & $3(6.66 \%)$ & $2(4.44 \%)$ \\
\hline & Deep & $1(2.22 \%)$ & Nill \\
\hline Non-union & & $1(2.22 \%)$ & $2(4.44 \%)$ \\
\hline Knee pain & & $4(8.88 \%)$ & $10(22.22 \%)$ \\
\hline $\begin{array}{c}\text { Average knee } \\
\text { flexion after } 6 \\
\text { months }\end{array}$ & - & $118.93 \pm 17.30$ & $109.03 \pm 18.78$ \\
\hline
\end{tabular}

The youngest patient was a 20 year old female and the oldest one was 78 year old female patient. Maximum patients were between 40 years and 60 years age group. Sex and age distribution was very similar in both-groups.

High energy trauma (Road Traffic accidents, railway injuries, fall from heights etc) was noted in 55 patients (61.11\%) [LCP group $62.22 \%$ (28 patients), SCN group 60\% (27 patients)] and low energy impact in 35patients (38.88\%) [LCP group $37.77 \%$ (17 patients), SCN group 40\% (18 patients)].

Out of 90 patients, 38 were open and 52 were close type fractures. The nature of such fractures was about same in LCP (open-42.22\%) and SCN group (open-42.22\%) groups.

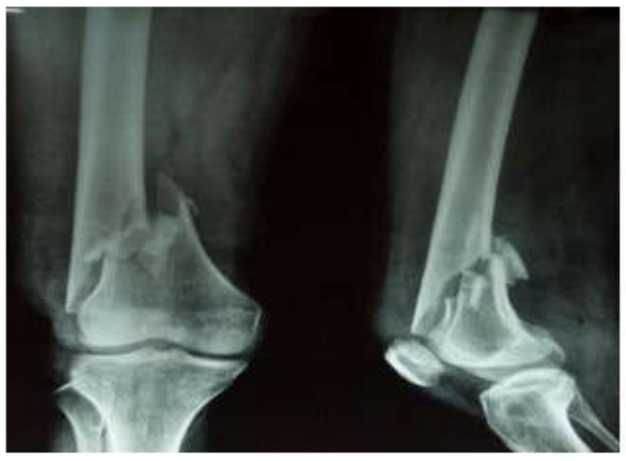

PREOP

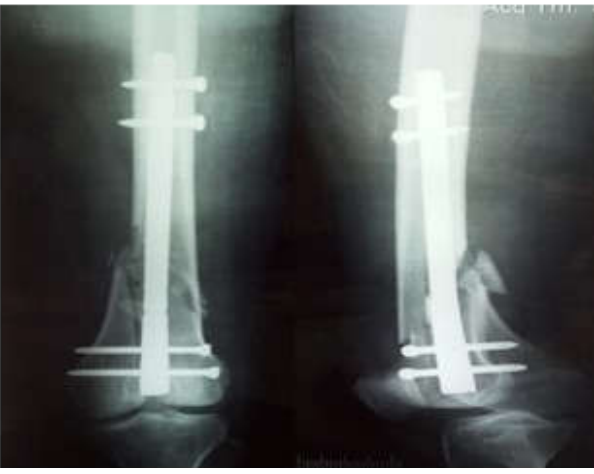

POSTOP 


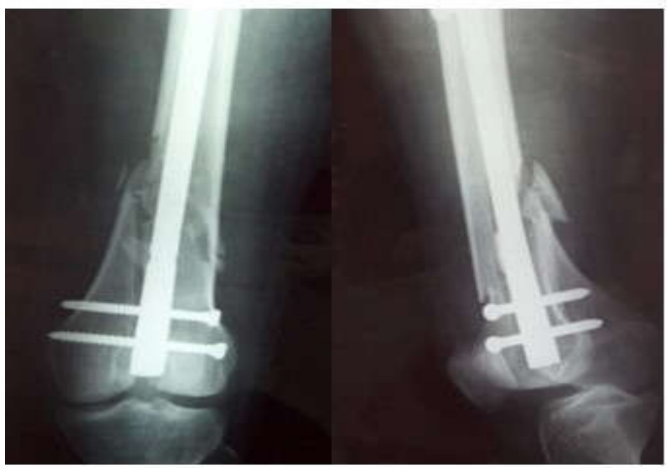

POST OP 2 WEEKS
Original Research Article

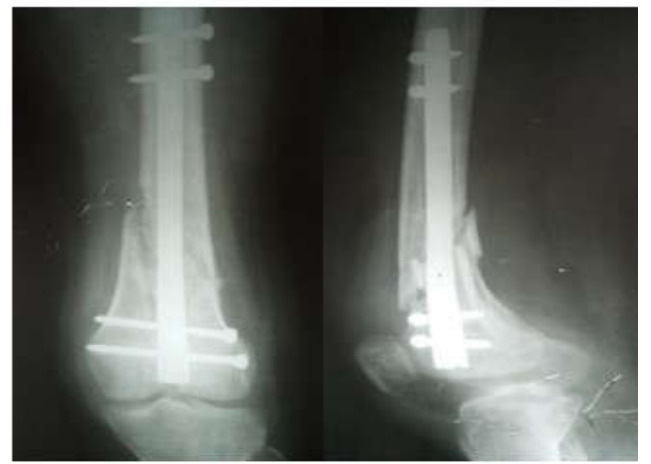

POST OP 6 WEEKS

Figure 1: Fracture treated with supra condylar nailing

In the LCP group 1 out of 45 patients $(2.22 \%)$ developed non-union at 9 months after osteosyn thesis. In the SCN group 2 out of 45 patients (4.44\%) developed non-union requiring surgery with bone grafting.

In our study majority of patients were males. Sex distribution was quite similar in both groups with $64.44 \%$ males in LCP group and $68.88 \%$ males in SCN group. Male predominance may be due to their being more prone to high velocity trauma than females.

In our study, 5 patients ( 3 in LCP group and 2 in SCN group) developed superficial infection and 1 patient developed deep infection (LCP group), while post op pain was much more common in the nailing group after supracondylar nailing (10 cases) $(22.22 \%)$ than plating ( 4 cases) $(8.88 \%)$.

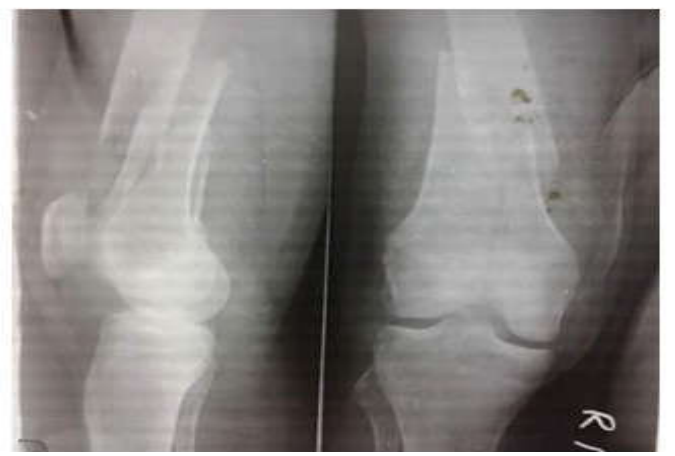

Preop

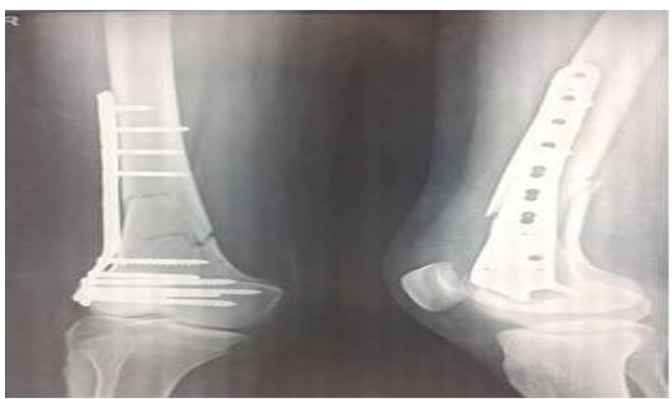

Post op 2 weeks

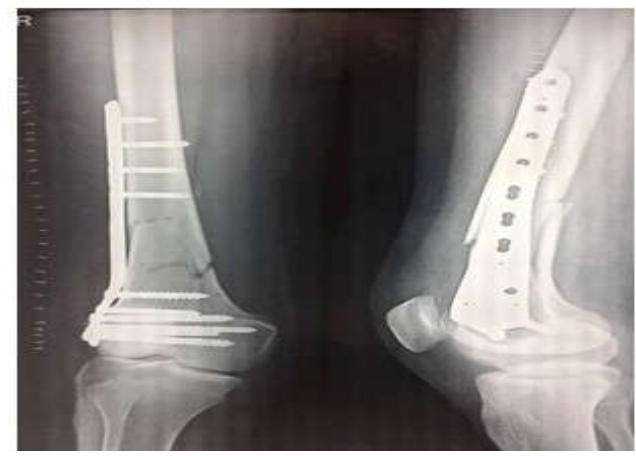

Postop

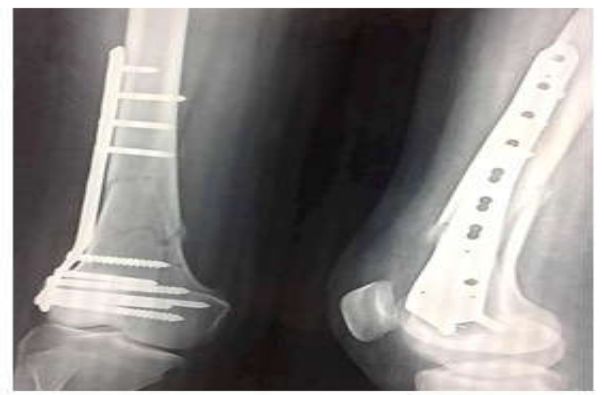

Post op 6 weeks

Figure 2: Fracture treated with LCP

Knee pain was more common (22.22\% vs $8.88 \%$ ) after nailing as compared to plating. This may be most likely because the nailing might have affected the knee and its flexion postoperatively. 


\section{Original Research Article}

Average range of movement was $96.33^{\circ} \pm 8.03^{\circ}$ in the LCP group and $90.83^{\circ} \pm 8.84^{\circ}$ in the $\mathrm{SCN}$ group at the end of 8 weeks ( $\mathrm{t}$ $=2.5225, \mathrm{df}=58, \mathrm{p}=0.0144)$. The range of movement improved to $118.93^{\circ} \pm 17.30^{\circ}$ in the LCP group and $109.03^{\circ} \pm 18.78^{\circ}$ in the $\mathrm{SCN}$ group by 6 months follow up after vigorous physiotherapy $(\mathrm{t}=2.1236, \mathrm{df}=58, \mathrm{p}=0.0380)$. So flexion at knee was better in LCP group than $\mathrm{SCN}$ group.

Table-3: Outcomes of supracondylar femur fractures treated with LCP and SCN.

\begin{tabular}{|c|c|c|c|c|c|c|}
\hline \multirow{2}{*}{ Grade } & \multicolumn{2}{|c|}{ LCP group } & \multicolumn{2}{c|}{ SCN group } & \multicolumn{2}{c|}{ Overall } \\
\cline { 2 - 7 } & No. of cases & $\mathbf{\%}$ & No. of cases & $\%$ & No. of cases & $\%$ \\
\hline Excellent & 28 & 62.22 & 22 & 48.88 & 50 & 55.55 \\
\hline Good & 12 & 26.66 & 9 & 20.00 & 21 & 23.33 \\
\hline Fair & 2 & 4.44 & 6 & 13.33 & 8 & 8.88 \\
\hline Poor & 3 & 6.66 & 8 & 17.77 & 11 & 12.22 \\
\hline
\end{tabular}

Other Contributing factors which affected the results:

a. Better results in simple fracture than compound fracture.

b. Better results in type A fractures than type $C$ fractures.

c. Intramedullary nailing may be better suited procedure in bilateral extremities fractures.

d. Main limiting factors of supracondylar nail are persistent knee pain and inability to use in complex type $\mathrm{C}$ fractures.

e. Inferior result in comminuted fractures.

f. Locking plate can be utilized for all supracondylar femur fractures including periprosthetic and osteoporotic fractures.

g. Good quality of operative technique is important for better clinical results.

\section{Discussion}

Inthe current studyon supracondylarfemur fractures, average age group was 51years with male predominance. Our study was carriedinasemi-rural area and majority of the sample had men who were working as labourers.

Gender predilection: The study done by Lucas etal. showed similar results to our study which showed preponderance of younger patients [15]. This was in contrast to the studies conducted by Gellmannetal and Watanabe et al which showed higher number of older patients $[13,14]$. High female preponderance was seen in older age group, while high male preponderance was seen in the younger age group. This may be attributed to the higher incidence of road traffic accidents seen in young males.

Mode of injury: In the present study, road traffic accident accounted for $56 \%$ of cases. These findings matched with those observed by Gellmanetal and Schatzkeretalwho also observed traumaas the most common cause $[13,16]$ of such fractures.

\section{Average time to union with plating:}

Radiological union was defined as bridging callusacross threecortices. In the present study average time to union for platingwasaround 15 weeks, which was comparable to the findings of the studies done by Hendersonetal and Markmilleretal whoob servedittobe 12 and14 weeksrespectively [17,18]. Similar duration of 11-14 weeks was observed by other authors [18-22].

\section{Average time to union with nailing:}

In the present study, average time to union for nailingwas 13 weeks, thiswas similar to the results noted in the study done by Gellmannetal, Kumaret al and Ingmanetal who recorded these as average durations of 12 weeks, 14 weeks and 12 weeks respectively $[23,13,24]$.

\section{Comparison of average union in weeks for Nailing and Plating:}

Average healing time / time to Union for Nailing was better the plating. The time to union for nailing was 13.4 weeks and that for Plating was 15.6 weeks. The management of more complex, comminuted fractures (Muller type C) with Plating may have contributed to delayed healing time with use of plates.

\section{Comparison of knee flexion in plating and nailing:}

In this study, the range of motion was better in the nailing group (112degrees) compared to that seen in the plating group (107degrees). The reason for this difference may be due to the fact that knee mobilization was started early in the nailing group than the plating group. Complex and comminuted fractures usually need more stable fixation hence are mostly treated by plating. In the plating group there may have been a delay in mobilization which may have contributed to relatively poor knee ROM as compare to Nailing group. Our results matched those of Lucas et al, Gellman et al, [15] Kumar et al [23], Ingman et al who reported 104,106,100,102 degrees of average knee flexion respectively with the use of nailing procedures. For 
plating procedures our study reported similar results to the ones noted by Kregoret al [14,25] Schutzetal [20], Mark Milleretal who reported average knee flexion of 103,107 and 110 degrees respectively [17,22].

\section{Average time of surgery:}

In the present study the average time taken for nailing procedure or surgery was 104.8 minutesand that for Plating procedure was 117.5 minutes.

\section{Rate of Non-unions in Nailing and Plating:}

In our study the rate of non-union for cases treated by nailing was $2.22 \%$ which is comparable to the observations made by Kumaretal which were 2\% [23].

However, in the Plating group we observed a non-union rate of $4.44 \%$ which is quite less as compared to those reported by Kregoretal (7\%) and by Schutzetal (5\%) $[22,20]$. The difference in the non-union rates between nailing and plating groups was found to be almost double.

\section{Implant failure rate in Nailing and Plating:}

Obgemudia etal observed a rate of $3.4 \%$ of failure of implants in the nailing group, these are almost similar to $2.7 \%$ seen in our study [25]. Kregoretal and Schutzetal observed rates of $1.5 \%$ and $6 \%$ respectively $[22,20]$ of failure of implants in the plating group. We found a $3.6 \%$ failure rate in the Plating series. In the current study we observed almost similar implant failure rates between the nailing and plating group.

Previous studies showed that failure rate was predominantly seen in plating series when compared to nailing series. Now with improved plating procedures and implants these failure rates have substantially reduced.

There are certain disadvantages of the nailing like difficulty in achieving the alignment, difficulty in control of angulations, accidental perforation of joint and decreased stability with small diameter nails.

The management of Supracondylar fracture is challenging with high potential risk of morbidity. Most failures are because of inadequate fixation of the fracture.

The prognostic factors include age, intraarticular involvement, treatment methods used and time when the range of motion is initiated. It is difficult to compare the results of different reported series because of different demographic distribution, different patient characteristics, different classification-systems and variable functional rating-systems used in different studies.

\section{Conclusion}

To summarize LCP had better results than SCN in all parameters especially when used for intra articular fractures. Thus, we conclude that locking plates are the better implants in almost all ways than SCN in managing supracondylar fracture of femur.

Limitations- The sample size of this study was small and also study period. We are continuing this study further and will report results at the end of five years follow up. We need studies with big sample size and with a long duration of follow-up.

Conflict of interest: None declared.

Funding: Nil, Permission from IRB: Yes

\section{References}

1. Kolmert L, Wulff K. Epidemiology and treatment of distal femoral fractures in adults. Acta Orthop Scand. 1982 Dec;53 (6):957-62.

2. Martinet O, Cordey J, Harder Y, Maier A, Bühler M, Barraud GE. The epidemiology of fractures of the distal femur. Injury. 2000 Sep;31 Suppl 3:C62-3.

3. Arneson TJ, Melton LJ 3rd, Lewallen DG, O'Fallon WM. Epidemiology of diaphyseal and distal femoral fractures in Rochester, Minnesota, 1965-1984. Clin Orthop Relat Res. 1988 Sep;(234):188-94.

4. Kretttek C, Schandelmeier P, Tscherne H. Distal femoral fractures. Unfallchirurg. 1996; 90:2.

5. Albert MJ.SupracondylarFractures of the Femur. J Am AcadOrthop Surg.1997 May;5(3):163-171.

6. Ruedi T, Murphy WM (2000) AO Principles of Fracture Management. Vol. 1. Thieme: Stuttgart-New York.

7. Schatzker J, Lambert DC. Supracondylar fractures of the femur.ClinOrthopRelat Res.1979Jan-Feb;(138):77-83.

8. Smith WR, Ziran BH, Anglen JO, Stahel PF. Locking plates: tips and tricks.J Bone Joint Surg Am.2007 Oct; 89 (10): 2298-307.

9. Zlowodzki M, Williamson S, Cole PA, Zardiackas LD, Kregor PJ. Biomechanical evaluation of the less in vasivestabilization system, angledbladeplate, and retrogradeintramedullarynail for the internal fixation of distalfemur fractures. J Orthop Trauma. 2004 Sep;18 (8): 494-502. 


\section{Original Research Article}

10. Roos EM, Roos HP, Lohmander LS, Ekdahl C, Beynnon BD. Knee Injury and Osteoarthritis Outcome Score (KOOS) and HSS-development of a selfadministered outcome measure Orthop Sports Phys Ther 1998; 2888-96.

11. Zlowodzki M, Bhandari M, Marek DJ, Cole PA, Kregor PJ. Operativetreatment of acute distalfemur fractures: systematic review of 2 comparative studies and 45 case series (1989 to 2005). J Orthop Trauma. 2006 May; 20 (5):366-71.

12. Carmack DB, Berton RM, Kingston C, Zmurko M, Watson JT, Richardson M. Identification of the optimal intercondylar starting point for retrograde femoral nailing: an anatomic study. J Trauma. 2003 Oct;55(4):692-5.

13. Gellman RE, Paiement GD, Green HD, Coughlin RR. Treatment of supracondylar femoral fractures with a retrograde intramedullary nail. ClinOrthopRelat Res. 1996 Nov; (332):90-7.

14. Watanabe Y, Takai S, Yamashita F, Kusakabe T, Kim W, Hirasawa Y. Second-generation intramedullary supra condylar nail for distal femoral fractures. Int Orthop. 2002; 26(2):85-8.

15. Lucas. Quoted by Rockwood CA, Green DP. Fractures in adult,45h ed,Vol.II, pg.1972-93,1996.

16. Schatzker J, Horne G, Waddell J. The Toronto experience with supracondylarfractures offemur.Injury 6, pg.113-28,1975.

17. Markmiller M, Konrad G, Südkamp N. Femur-LISS and distal femoral nail for fixation of distal femoral fractures: are there differences in outcome and complications? ClinOrthopRelat Res. 2004 Sep; (426): 252-7.

18. Henderson CE, Lujan TJ, Kuhl LL, Bottlang M, Fitzpatrick DC, Marsh JL. 2010 mid-America
Orthopaedic Association Physician in Training Award: healing complications are common after lockedplating for distal femur fractures. ClinOrthopRelat Res. 2011 Jun;469 (6): 1757-65. doi: 10.1007/s11999-011-1870-6. Epub 2011 Mar 22.

19. Weight M, Collinge C. Early results of the less invasive stabilization system for mechanically unstable fractures of the distalfemur (AO/OTA types A2, A3, C2, and C3). JOrthop Trauma. 2004 Sep;18(8):503-8.

20. Kregor PJ, Stannard JA, Zlowodzki M, Cole PA. Treatment of distal femur fractures using the less invasive stabilization system: surgical experience and early clinical results in 103 fractures. J Orthop Trauma. 2004 Sep;18(8): 509-20.

21. Schandelmaier P, Partenheimer A, Koenemann B, Grün OA, Krettek C. Distal femoral fractures and LISS stabilization. Injury. 2001 Dec; 32 Suppl 3: SC 5563.

22. Schütz M, Müller M, Krettek C, Höntzsch D, Regazzoni P, Ganz R, Haas N. Minimally invasive fracture stabilization of distalfemoral fractures with the LISS: a prospective multicenter study. Results of a clinical study with special emphasis on difficult cases. Injury. 2001 Dec;32 Suppl 3:SC48-54.

23. Kumar A, Jasani VM, Butt MS. Management of distal femoral fractures in elderly patients using retrograde titanium supracondylar nails. Injury, 31(3): 169-73, Apr2000.

24. Ingman AM. Retrograde intramedullary nailing of supracondylar femoral fractures: design and development of a new implant. Injury. 2002 Oct;33(8):707-12.

25. OgbemudiaAO, UmebesePFA. Implant failure in osteosynthesis of fractures of long bones.JMBR: A Peerreview Journal of Biomedical Sciences 2006; 5 (2): $75-78$.

\section{How to cite this article?}

Shroff A. S, Bhamare D. S, Herode P, Sadaria M. H, Patel J. M. Comparison of outcomes of supracondylar femur fractures treated with locking compression plate vs supracondylar nail. Surgical Update: Int J surg Orthopedics. 2017;3(4):120126.doi:10.17511/ijoso.2017.i04.05. 